\title{
Sikap Ayah dan Jumlah Anak serta Praktik Air Susu Ibu Eksklusif
}

\author{
Father's Attitude and Number of Children toward Exclusive Breastfeeding \\ Practice
}

\author{
Suci Destriatania* Judhiastuty Februhartanty** Fatmah***
}

\begin{abstract}
*Fakultas Kesehatan Masyarakat Universitas Sriwijaya Palembang, **SEAMEO REFCON Regional Center for Food and Nutrition Universitas Indonesia, ***Fakultas Kesehatan Masyarakat Universitas Indonesia
\end{abstract}

\begin{abstract}
Abstrak
Partisipasi ayah pada pola pemberian makan bayi harus dipersiapkan dengan baik sehingga mendukung ibu untuk menyusui. Penelitian ini bertujuan untuk mengetahui hubungan antara pengetahuan dan sikap ayah terhadap praktik pemberian ASI eksklusif. Sampel dalam penelitian ini adalah 536 pasangan suami istri yang mempunyai bayi usia $0-6$ bulan. Data dikumpulkan dengan menggunakan kuesioner terstruktur. Desain yang digunakan adalah potong lintang dan analisis data menggunakan kai kuadrat dan regresi logistik. Rata-rata pemberian ASI eksklusif pada saat wawancara adalah $29,1 \%$. Sekitar $83,6 \%$ dan $59,1 \%$ ayah mempunyai pengetahuan rendah tentang manajemen laktasi prenatal dan postnatal, tetapi $89,6 \%$ dan $61,9 \%$ ayah menunjukkan sikap positif terhadap praktik menyusui ketika masa kehamilan dan menyusui. Dukungan ayah terhadap praktik menyusui justru rendah pada saat persalinan (37,3\%). Sikap ayah selama masa menyusui (nilai $p<0,05 ; \mathrm{OR}=1,623 ; 95 \% \mathrm{Cl}=1,086-2,425$ ) merupakan faktor yang paling dominan memengaruhi praktik pemberian ASI eksklusif setelah dikontrol faktor lainnya dalam analisis regresi logistik. Pengetahuan yang baik dan sikap yang positif diketahui sebagai faktor penting dalam keberhasilan praktik pemberian ASI eksklusif. Hal ini menunjukkan kebutuhan keterlibatan ayah dalam berbagai program promosi praktik menyusui.

Kata kunci: ASI eksklusif, multipara, pengetahuan ayah, sikap ayah
\end{abstract}

\section{Abstract}

Fathers participation in the decision making of infant feeding method have to be well prepared so that they can support mothers to breastfeed. The objective of the paper is to analyze the relationship between knowledge and attitude of the fathers on exclusive breastfeeding practice. Couples whose baby aged $0-6$ months were recruited in this study. Structured questionnaire was used to collect the data. The study design was cross sectional in which chi square and logistic regression analyses were used for the statistical tests. The prevalence of exclusive breastfeeding at time of interview was $29.1 \%$. Around $83.6 \%$ and $59.1 \%$ of fathers had low level of knowledge on prenatal and postnatal lactation management but $89.6 \%$ and $61.9 \%$ had positive attitude toward breastfeeding. Only $37.3 \%$ fathers showed positive attitude about breastfeeding during labor. Attitude of fathers during nursing period was a dominant factor associated with exclusive breastfeeding ( $\mathrm{p}$ value $<0.05 ; \mathrm{OR}=1.623 ; 95 \% \mathrm{Cl}=1.086-2.425$ ) after controlling for other factors in the logistic regression analysis. Good knowledge and positive attitude were known as important factors for successful exclusive breastfeeding practice. This indicates a need of breastfeeding education for fathers.

Keywords: Exclusive breastfeeding, multipara, father's knowledge, father's attitude

\section{Pendahuluan}

Pemberian ASI eksklusif banyak manfaat untuk ibu, bayi dan lingkungan sosial, tetapi dengan cakupan yang masih tergolong rendah. Survei Demografi Kesehatan Indonesia (SDKI) tahun 2012, menemukan pemberian ASI eksklusif di Indonesia dari tahun 2007 (32\%) meningkat pada tahun 2012 menjadi 42\%. ${ }^{1}$ Namun, secara nasional, peningkatan dalam kurun waktu lima tahun tersebut belum memuaskan, mengingat telah banyak upaya promosi pemberian ASI eksklusif yang telah dilakukan. Studi tentang determinan praktik menyusui di Indonesia cenderung terfokus pada faktor ibu, anak dan biomedis lain. Ayah yang berperan penting pada keberhasilan praktik menyusui adalah sumber dukungan selama periode menyusui, sejak pertama bayi dilahirkan

Alamat Korespondensi: Judhiastuty Februhartanty, SEAMEO RECFON Regional Center for Food and Nutrition, Jl. Salemba Raya No. 6 Kampus Salemba UI Jakarta 10430, Hp.08129260634, e-mail: judhiastuty@yahoo.com 
hingga enam bulan pertama kehidupan. Namun, studi tentang faktor ayah, seperti pengetahuan, sikap, dan peran terhadap praktik menyusui relatif terbatas. Pengaruh ayah meliputi membuat keputusan tentang pola pemberian makan bayi yang biasa dilakukan sejak awal kehamilan, mendampingi ibu ketika pertama kali menyusui, memengaruhi durasi menyusui, dan penggunaan susu formula. ${ }^{2}$

Dukungan ayah terlihat pada partisipasi aktif dalam pengambilan keputusan tentang pola pemberian makan bayi serta sikap positif dan pengetahuan yang berpengaruh kuat terhadap inisiasi dan durasi menyusui. ${ }^{2}$ Pengetahuan yang cukup diperlukan ayah untuk mengatasi berbagai kesulitan yang menghambat praktik menyusui serta menghadapi pandangan salah tentang praktik pemberian ASI. Pengetahuan ayah yang baik berhubungan signifikan dengan dukungan terhadap menyusui, calon ayah yang mendukung pola pemberian ASI pada bayi berpengetahuan yang lebih baik. ${ }^{3}$ Fathering Program yang mengedukasi ayah tentang berbagai faktor seputar menyusui berdampak positif, sekitar $69 \%$ bayi masih disusui hingga enam bulan pertama. ${ }^{4}$ Saat ini, ayah yang belum dilibatkan secara maksimal dalam berbagai program menyusui skala nasional, belum dipersiapkan secara optimal untuk mendukung dan membantu ibu menyusui.

Tanpa pengetahuan cukup tentang menyusui, ayah yang cenderung bersikap negatif terhadap praktik menyusui cenderung merencanakan pemberian susu formula pada bayi mereka. Sebaliknya, dengan pengetahuan yang lebih baik dan sikap positif terhadap menyusui, ayah cenderung merencanakan pola pemberian ASI pada bayi mereka. ${ }^{5}$ Tujuan penelitian ini adalah untuk mengetahui hubungan antara karakteristik sosiodemografi ayah, pengetahuan, dan sikap ayah terhadap praktik pemberian ASI eksklusif di wilayah Jakarta Selatan.

\section{Metode}

Penelitian ini menggunakan sumber data sekunder dengan desain potong lintang dari studi Peran Ayah Dalam Optimalisasi Praktik Pemberian ASI di Daerah Urban Jakarta oleh Februhartanty. ${ }^{6}$ Sebanyak 536 pasangan suami istri yang bersedia terlibat dalam studi serta memenuhi kriteria inklusi dan eksklusi diambil sebagai sampel. Sampel dalam studi ini adalah rumah tangga dengan ibu yang secara umum terlihat sehat, tinggal serumah dengan ayah kandung bayi, melahirkan bayi tunggal cukup bulan, dengan persalinan normal dan pernah menyusui bayi. Rumah tangga dengan bayi yang mempunyai kelainan cacat bawaan, pernah diletakkan di inkubator setelah dilahirkan selama lebih dari satu hari dan dengan berat lahir rendah tidak diikutkan dalam penelitian. Penelitian dilaksanakan di dua wilayah Jakarta Selatan, Kecamatan Pasar Minggu meliputi Kelurahan Pejaten Timur, Kebagusan dan Jati Padang serta Keca- matan Kebayoran Lama meliputi Kelurahan Pondok Pinang, Cipulir dan Grogol Selatan. Pemilihan kecamatan dan kelurahan dilakukan secara purposif berdasarkan jumlah kunjungan neonatus terbanyak dan jumlah kelahiran terbanyak yang tercatat di Suku Dinas Kesehatan Jakarta Selatan serta Puskesmas Kecamatan. Posyandu/RW yang terpilih adalah yang mempunyai jumlah bayi usia $0-6$ bulan terbanyak.

Informasi tentang praktik pemberian ASI eksklusif, karakteristik sosiodemografi meliputi usia, pendidikan, pekerjaan dan pendapatan, serta pengetahuan dan sikap tentang manajemen laktasi didapatkan melalui wawancara langsung menggunakan kuesioner terstruktur. Praktik pemberian ASI eksklusif saat wawancara diperoleh dari informasi bayi tidak menerima makanan/minuman selain ASI dalam 24 jam terakhir. Pengetahuan ayah tentang manajemen laktasi dikelompokkan menjadi beberapa tahap yang meliputi pengetahuan yang dikategorikan menjadi tingkat rendah atau tinggi dan pengetahuan postnatal dikategorikan menjadi tingkat rendah atau tinggi. Sikap ayah tentang manajemen laktasi juga dikelompokkan menjadi beberapa tahap, meliputi sikap selama masa kehamilan yang dikategorikan menjadi sikap negatif atau positif, sikap saat masa persalinan yang dikategorikan menjadi sikap negatif atau positif, dan sikap selama masa menyusui yang dikategorikan menjadi sikap negatif atau positif. Kategorisasi tingkat pengetahuan dan sikap ayah ditentukan berdasarkan jawaban benar untuk pengetahuan atau respons positif untuk sikap dengan batas $70 \%$ dari total skor.

Analisis univariat dilakukan untuk mendapatkan informasi tentang frekuensi dan persentase dari berbagai variabel yang diamati. Uji kai kuadrat digunakan untuk menganalisis hubungan variabel independen meliputi karakteristik sosiodemografi ayah, pengetahuan dan sikap ayah serta dependen pemberian ASI eksklusif yang berskala ordinal. Perbedaan bermakna dinyatakan jika nilai $\mathrm{p}<0,05$. Analisis multivariat dilakukan dengan regresi logistik untuk mengetahui berbagai faktor yang memengaruhi praktik pemberian ASI eksklusif. Variabel yang masuk ke dalam kandidat model multivariat diperoleh dari hasil analisis bivariat menggunakan uji potong lintang dengan kriteria nilai $p \leq 0,25$. Variabel dengan nilai $\mathrm{p}>0,05$ kemudian dikeluarkan dari model dengan prosedur backward stepwise.

\section{Hasil}

Penelitian ini menemukan bahwa 70,9\% bayi tidak diberi ASI eksklusif dan rata-rata usia ayah pada saat penelitian berlangsung adalah 32,95 tahun. Mayoritas ayah $(68,5 \%)$ yang berpendidikan menengah berhasil menyelesaikan pendidikan di tingkat SMA, akademi dan universitas. Sebesar 51,1\% bekerja di sektor formal sebagai pegawai negeri sipil atau pegawai swasta dan 
49,6\% berpendapatan di atas upah minimum propinsi (UMP) DKI Jakarta tahun 2007 sekitar Rp800,000. Diketahui pula bahwa sebagian besar ayah mempunyai anak lebih dari 1 orang $(61,8 \%)$ dan tinggal sebagai keluarga inti $(51,3 \%)$ (Tabel 1).

Berdasarkan skoring, studi ini menemukan mayoritas ayah mempunyai pengetahuan yang rendah tentang manajemen laktasi prenatal $(83,6 \%)$ dan postnatal $(59,1 \%)$. Masih banyak ayah yang belum mengetahui kolostrum $(95,7 \%)$ dan keuntungannya $(72,8 \%)$. Lebih dari separuh ayah tidak mengetahui keuntungan bayi disusui segera $(55,8 \%)$, lama pemberian ASI eksklusif $(55,2 \%)$ dan usia sebaiknya bayi mulai menerima susu formula $(63,8 \%)$. Sekitar $55 \%$ ayah mengetahui solusi tetap memberikan ASI ketika ibu kembali bekerja (Tabel 2).

Sebagian besar ayah menunjukkan sikap positif pada masa kehamilan $(89,6 \%)$. Namun, berbeda halnya dengan sikap yang ditunjukkan ayah pada saat kelahiran. Hanya $37,3 \%$ ayah yang menunjukkan sikap positif terhadap praktik pemberian ASI. Hal ini terlihat seperti pada Tabel 3 bahwa ayah menyetujui untuk memberikan madu atau air $(62,5 \%)$ dan susu formula $(74,1 \%)$ kepada bayi setelah dilahirkan sebagai pengganti ASI sebelum ASI keluar. Selain itu, sebesar $88,1 \%$ ayah cenderung mengikuti nasihat petugas kesehatan. Sebesar $85,4 \%$ ayah berpendapat bahwa apa yang dilakukan petugas kesehatan pada bayinya adalah yang terbaik.

Walaupun sebagian besar ayah $(61,9 \%)$ mendukung ibu untuk menyusui, tetapi ada beberapa pernyataan sikap yang harus dicermati karena akan dapat menghambat kesuksesan pemberian ASI eksklusif. Tabel 3 menunjukkan bahwa mayoritas ayah setuju susu formula dapat diberikan pada bayi di bawah usia enam bulan $(93,3 \%)$ dan sebagian besar $(66,6 \%)$ berpendapat anak menangis merupakan pertanda kuantitas ASI ibu sedikit atau kurang memenuhi kebutuhan anak. Diketahui pula bahwa sebesar 58\% ayah tidak mengizinkan ibu menyusui di tempat umum. Pembagian tanggung jawab yang masih kaku antara suami istri juga terlihat masih dominan. Sebesar $73,1 \%$ ayah setuju bahwa tugas mereka adalah mencari nafkah dan tugas istri adalah mengurusi segala keperluan rumah tangga dan keluarga.

Analisis multivariat dengan uji regresi logistik dilakukan untuk mengetahui secara bersamaan pengaruh karakteristik sosiodemografi, pengetahuan dan sikap ayah terhadap praktik pemberian ASI eksklusif. Terdapat 8 variabel yang terseleksi (nilai $p<0,25$ ) untuk masuk dalam model awal analisis multivariat, meliputi usia, status pekerjaan, jumlah anak, komposisi keluarga, pengetahuan manajemen laktasi prenatal, pengetahuan manajemen laktasi postnatal, sikap selama kehamilan dan sikap selama masa menyusui. Variabel-variabel yang tidak signifikan kemudian dikeluarkan dari model menggunakan prosedur backward stepwise. Model akhir me-
Tabel 1. Karakteristik Sosiodemografi

\begin{tabular}{llll}
\hline Karakteristik & Kategori & n & $\%$ \\
\hline Usia & $\leq 32,95$ & 269 & 50,2 \\
\multirow{2}{*}{ Pendidikan } & $>32,95$ & 267 & 49,8 \\
& Dasar & 169 & 31,5 \\
Pekerjaan & Menengah & 367 & 68,5 \\
& Tidak bekerja & 10 & 1,9 \\
\multirow{3}{*}{ Pendapatan } & Sektor informal & 252 & 47,0 \\
\multirow{2}{*}{ Jumlah anak } & Sektor formal & 274 & 51,1 \\
& $\leq$ UMP DKI Jakarta & 265 & 50,4 \\
Komposisi rumah tangga & > UMP DKI Jakarta & 261 & 49,6 \\
& > 1 orang & 331 & 61,8 \\
& 1 orang & 205 & 38,2 \\
& Keluarga inti & 275 & 51,3 \\
& Bukan keluarga inti & 261 & 48,7 \\
\hline
\end{tabular}

Tabel 2. Pengetahuan Ayah Tentang Manajemen Laktasi Prenatal dan Postnatal

\begin{tabular}{lll}
\hline & \multicolumn{2}{c}{ Jawaban Benar } \\
\cline { 2 - 3 } Pertanyaan Pengetahuan & $\mathbf{n}$ & $\%$ \\
\hline Masa Prenatal & & \\
Keuntungan menyusui & 511 & 95,3 \\
Arti kolostrum & 23 & 4,3 \\
Keuntungan kolostrum & 146 & 27,2 \\
Susu formula sama baik dengan ASI & 509 & 95,0 \\
Satu kesulitan menyusui & 390 & 72,8 \\
Yang dapat dilakukan suami membantu kesulitan menyusui & 361 & 67,4 \\
& & \\
Masa Postnatal & & \\
Anak sehat & 528 & 98,5 \\
Keuntungan rawat gabung & 410 & 76,5 \\
Keuntungan bayi disusui ASI segera setelah dilahirkan & 237 & 44,2 \\
Usia bayi seharusnya hanya diberikan ASI & 240 & 44,8 \\
Usia sebaiknya bayi menerima susu formula & 194 & 36,2 \\
Keuntungan pemberian ASI hingga dua tahun & 410 & 76,5 \\
Cara ibu yang bekerja dapat tetap menyusui bayinya & 297 & 55,4 \\
Frekuensi anak harus dapat ASI & 422 & 78,7 \\
Tanda-tanda anak yang telah cukup minum ASI & 493 & 92,0 \\
\hline
\end{tabular}

nemukan variabel yang berhubungan signifikan dengan praktik pemberian ASI eksklusif adalah paritas ayah (nilai $\mathrm{p}=0,003$; $\mathrm{OR}=0,537 ; 95 \% \mathrm{CI}=0,358-0,806$ ) dan sikap ayah selama masa menyusui (nilai $\mathrm{p}=0,018$; $\mathrm{OR}=1,623 ; 95 \% \mathrm{CI}=1,086-2,425)$. Interpretasi hasil analisis bahwa kecenderungan praktik ASI eksklusif adalah sekitar 0,54 kali pada ayah yang mempunyai satu anak dibandingkan dengan ayah yang mempunyai lebih dari satu anak. Dengan kata lain, ibu satu anak mempunyai kecenderungan lebih kecil untuk mempraktikkan ASI eksklusif dibandingkan dengan ibu yang mempunyai anak lebih dari satu orang. Namun, praktik pemberian ASI eksklusif cenderung 1,62 kali lebih tinggi pada ibu yang mendapat dukungan dari ayah untuk menyusui selama masa menyusui dibandingkan ibu yang tidak mendapat dukungan dari ayah untuk menyusui (Tabel 4).

\section{Pembahasan}

Studi ini menemukan bahwa ibu yang mempunyai 
Tabel 3. Pernyataan Sikap Ayah terhadap Praktik Menyusui

\begin{tabular}{|c|c|c|c|c|c|c|}
\hline \multirow{2}{*}{ Pernyataan Sikap Ayah } & \multicolumn{2}{|c|}{ Setuju } & \multicolumn{2}{|c|}{ Netral } & \multicolumn{2}{|c|}{ Tidak Setuju } \\
\hline & n & $\%$ & n & $\%$ & $\mathbf{n}$ & $\%$ \\
\hline \multicolumn{7}{|l|}{ Selama Kehamilan } \\
\hline Status gizi selama hamil tidak memengaruhi produksi dan kualitas ASI & 114 & 21,3 & 70 & 13,1 & 352 & 65,7 \\
\hline Suami menemani saat pemeriksaan kehamilan & 502 & 93,7 & 25 & 4,7 & 9 & 1,7 \\
\hline Setuju istri menyusui anak terkecil & 528 & 98,0 & 0 & 0 & 8 & 1,5 \\
\hline Selalu mengikuti nasihat petugas kesehatan & 472 & 88,1 & 43 & 8,0 & 21 & 3,9 \\
\hline Mendukung ASI hingga bayi usia dua tahun & 426 & 79,5 & 44 & 8,2 & 66 & 12,3 \\
\hline Pengetahuan gizi dan kesehatan anak cukup & 261 & 48,7 & 217 & 40,5 & 58 & 10,8 \\
\hline \multicolumn{7}{|l|}{ Saat Kelahiran } \\
\hline Menemani istri di ruang bersalin & 436 & 81,3 & 59 & 11,0 & 41 & 7,6 \\
\hline Bayi segera diberi ASI $30-60$ menit setelah lahir & 450 & 84,0 & 40 & 7,5 & 46 & 8,6 \\
\hline Tidak segera menyusui, bayi kesulitan menyusui & 347 & 64,7 & 86 & 16,0 & 103 & 19,2 \\
\hline Disarankan memberi madu atau air sebelum ASI keluar & 335 & 62,5 & 72 & 13,4 & 29 & 24,1 \\
\hline Sebelum ASI keluar, bayi boleh diberi susu formula & 397 & 74,1 & 38 & 7,1 & 101 & 18,8 \\
\hline Tenaga kesehatan melakukan yang terbaik pada bayi kami & 458 & 85,4 & 59 & 11,0 & 19 & 3,5 \\
\hline \multicolumn{7}{|l|}{ Selama Menyusui } \\
\hline Bayi hanya diberikan ASI sampai usia enam bulan & 338 & 63,1 & 46 & 8,6 & 152 & 28,4 \\
\hline Makin sering disusui, makin banyak ASI keluar & 498 & 92,9 & 21 & 3,9 & 17 & 3,2 \\
\hline Ibu makin banyak makan, makin banyak ASI & 482 & 84,9 & 30 & 5,6 & 24 & 4,5 \\
\hline ASI dapat dipompa dan diberikan pada bayi & 334 & 62,3 & 42 & 7,8 & 160 & 29,9 \\
\hline Istri tidak boleh menyusui di termpat umum & 311 & 58,0 & 80 & 14,9 & 145 & 27,1 \\
\hline ASI makanan utama bayi usia $<6$ tahun & 500 & 93,3 & 14 & 2,6 & 22 & 4,1 \\
\hline Saat istri kesal, ASI menjadi kurang & 231 & 43,1 & 128 & 23,9 & 177 & 33,0 \\
\hline Suami dapat menjadi sumber kekesalan istri & 313 & 58,4 & 93 & 17,4 & 130 & 24,3 \\
\hline Menangis setelah disusui, tanda ASI kurang & 357 & 66,6 & 55 & 10,3 & 124 & 23,1 \\
\hline Susu formula lebih praktis daripada ASI & 105 & 19,6 & 43 & 8,0 & 388 & 72,4 \\
\hline ASI lebih murah daripada susu formula & 482 & 89,9 & 15 & 2,8 & 39 & 7,3 \\
\hline Bapak merasa tersisih ketika istri menyusui & 73 & 13,6 & 59 & 11,0 & 404 & 75,4 \\
\hline Keberhasilan menyusui tidak perlu dukungan suami & 168 & 31,3 & 62 & 11,6 & 306 & 57,1 \\
\hline Suami mencari nafkah, istri mengurus keluarga & 392 & 73,1 & 61 & 11,4 & 83 & 15,5 \\
\hline Bapak lebih suka momong daripada pekerjaan rumah & 210 & 39,2 & 176 & 32,8 & 150 & 28,0 \\
\hline Suami tidak selalu dapat membantu di rumah & 165 & 30,8 & 97 & 18,1 & 274 & 51,1 \\
\hline Setelah punya anak, bapak puas dengan kehidupan rumah tangga & 492 & 91,8 & 26 & 4,9 & 18 & 3,4 \\
\hline Anak prioritas keluarga, istri tidak selalu dapat melayani & 411 & 76,7 & 70 & 13,1 & 55 & 10,3 \\
\hline
\end{tabular}

anak lebih dari satu orang mempunyai kecenderungan lebih tinggi untuk mempraktikkan ASI eksklusif. Ibu multipara merasa telah mempunyai pengalaman menyusui sebelumnya sehingga pengalaman sebelumnya ini dapat menjadi masukan untuk mempraktikkan pemberian ASI yang lebih baik kepada anak yang berikutnya. Dalam hubungannya dengan peran ayah, ayah perlu dipersiapkan dengan baik agar siap menghadapi peran barunya terutama dalam hal mendukung ibu untuk menyusui, mengingat perannya begitu penting mulai dari membuat keputusan tentang pola pemberian makan bayi, mendampingi ibu ketika pertama kali menyusui, memengaruhi durasi menyusui hingga berperan memutuskan penggunaan susu formula. ${ }^{2}$ Tetapi sayangnya tidak banyak kesempatan yang diberikan pada ayah untuk mempersiapkan dirinya agar dapat membantu dan mendukung ibu untuk menyusui. Pengetahuan tentang praktik menyusui dibutuhkan ayah untuk menghadapi mitos dan pemahaman yang salah tentang menyusui serta dapat membantu ibu dalam mengatasi kesulitan menyusui. ${ }^{3,5}$

Studi intervensi yang memberikan edukasi pada ayah tentang manajemen laktasi terbukti memberi dampak
Tabel 4. Model Akhir Hasil Analisis Multivariat Praktik Pemberian ASI Eksklusif

\begin{tabular}{lllll}
\hline Variabel & B & Nilai p & OR & 95\% CI \\
\hline Mempunyai satu anak & $-0,622$ & 0,003 & 0,537 & $0,358-0,806$ \\
Sikap positif selama masa menyusui & 0,484 & 0,018 & 1,623 & $1,086-2,425$ \\
Konstanta & $-0,984$ & 0,000 & 0,374 & \\
\hline
\end{tabular}

yang baik terhadap praktik menyusui. ${ }^{4,7}$ Pisacane $\mathrm{dkk},{ }^{7}$ dalam studinya menunjukkan bahwa informasi yang didapatkan ayah dari sesi pelatihan tentang manajemen laktasi dapat meningkatkan peran ayah dalam mendukung kesuksesan menyusui. Ayah diberikan informasi seperti bagaimana mengatasi volume ASI yang tidak cukup, masalah-masalah yang terkait dengan payudara serta bagaimana mengenali dan menerima peran pentingnya untuk mencapai kesuksesan praktik pemberian ASI. Prevalensi pemberian ASI eksklusif enam bulan lebih tinggi pada ayah di kelompok intervensi yang menerima informasi tentang manajemen laktasi $(25 \%)$ dibanding ayah pada kelompok kontrol yang hanya diberikan informasi tentang manfaat ASI saja (15\%). Hal serupa juga 
terlihat pada studi intervensi yang dilakukan di Los Angeles Departement of Water and Power (LA DWP) dengan memberikan edukasi pada ayah yang bertujuan agar ayah mengenali dan menerima peran pentingnya terhadap kesuksesan praktik menyusui. Informasi yang diberikan yaitu tentang perawatan dan penggunaan pompa ASI, penyimpanan ASI perah serta cara mengatasi kesulitan menyusui yang terkait dengan masalah payudara. Rata-rata durasi menyusu semua bayi yang ayahnya berpartisipasi dalam program tersebut adalah delapan bulan dimana sebesar $69 \%$ bayi tersebut masih menerima ASI eksklusif hingga enam bulan. ${ }^{4}$ Pada kedua studi intervensi tersebut, terlihat bahwa selain meningkatnya pengetahuan ayah, intervensi juga diarahkan untuk meningkatkan keterampilan ayah dalam manajemen laktasi.

Berdasarkan analisis multivariat, penelitian ini menemukan bahwa pengetahuan ayah bukan merupakan faktor dominan yang memengaruhi praktik pemberian ASI eksklusif melainkan sikap ayah selama periode menyusui. Hal ini terjadi karena pengetahuan tidak berdiri sendiri atau berpengaruh langsung terhadap praktik menyusui, melainkan dengan mempunyai pengetahuan yang baik akan mendorong ayah mempunyai sikap yang positif terhadap praktik menyusui.

Penelitian ini menunjukkan bahwa praktik pemberian ASI eksklusif berhubungan signifikan dengan sikap ayah selama masa menyusui. Praktik pemberian ASI eksklusif akan 1,6 kali lebih tinggi pada ayah yang bersikap positif terhadap praktik menyusui selama masa menyusui. Studi Arora dkk, ${ }^{8}$ menunjukkan bahwa ibu berniat akan menyusui bayinya jika ayah menunjukkan dukungan positif terhadap praktik menyusui. Sebaliknya, ibu akan memilih untuk memberikan susu formula jika ayah tidak mendukung praktik menyusui. ${ }^{2}$ Korelasi yang kuat antara pemilihan metode pemberian makan dengan sikap mengindikasikan bahwa sikap ayah merupakan proksi yang harus dipertimbangakan terhadap sikap ibu untuk menyusui atau tidak menyusui. ${ }^{9}$ Partisipasi aktif ayah dalam pengambilan keputusan pemberian ASI disertai dengan sikap positif dan pengetahuan yang baik tentang manfaat menyusui diketahui dapat memberi pengaruh kuat terhadap inisiasi menyusu segera dan durasi menyusui dalam jangka waktu lama. ${ }^{4,10}$

Dukungan ayah terhadap praktik menyusui kadang menjadi tidak konsisten karena beberapa alasan, diantaranya terganggunya hubungan seksual dengan pasangan, merasa terabaikan oleh ibu karena menyusui bayi, berkurangnya perhatian dari ibu karena sebagian besar waktunya terfokus pada pengasuhan bayi serta berkurangnya kesempatan untuk membina hubungan dengan bayi. ${ }^{2,10}$ Hal tersebut dapat berpengaruh negatif terhadap inisiasi dan rata-rata praktik pemberian ASI. ${ }^{7}$

Sikap ayah merupakan komponen penting bagi ibu dalam meneruskan pemberian ASI setelah meninggalkan tempat persalinan dan mengatasi masalah-masalah yang menghambat praktik menyusui, seperti masalah yang berkaitan dengan payudara (puting lecet, payudara bengkak, mastitis, abses payudara).11,12 Peran ayah bukan hanya sebatas pencari nafkah atau penopang ekonomi keluarga tetapi dapat pula menjadi sosok siaga di rumah dan juga teman berbagi tanggung jawab dalam hal pengasuhan anak dan penyelesaian tugas rumah tangga. Manfaat keterlibatan ayah dalam hal pengasuhan anak terlihat dari dukungan dan kasih sayang yang dirasakan oleh ibu terutama ketika melakukan tanggung jawab pengasuhan anak. ${ }^{13,14}$

\section{Kesimpulan}

Rata-rata praktik pemberian ASI eksklusif dalam penelitian ini masih terbilang rendah. Walaupun sebagian besar ayah mempunyai pengetahuan manajemen laktasi prenatal $(83,6 \%)$ dan postnatal $(59,1 \%)$ yang rendah tetapi sikap mereka terhadap praktik menyusui terutama pada masa kehamilan $(89,6 \%)$ dan menyusui $(61,9 \%)$ terbilang positif dibandingkan pada saat kelahiran. Bagaimanapun, sebagian besar ayah menunjukkan persetujuannya terhadap pemberian makanan prelakteal (air, madu, susu formula) kepada bayi sebelum ASI keluar dan percaya sepenuhnya pada tenaga kesehatan terkait dengan bayi mereka. Hal tersebut dapat menjadi risiko pemberian susu formula. Jumlah anak yang dimiliki, komposisi rumah tangga, pengetahuan manajemen laktasi postnatal dan sikap ayah selama masa menyusui diketahui berhubungan signifikan dengan praktik pemberian ASI eksklusif dimana jumlah anak dan sikap ayah selama masa menyusui merupakan faktor dominan yang berhubungan dengan praktik pemberian ASI eksklusif.

\section{Saran}

Ayah perlu dipersiapkan dengan baik untuk memberikan dukungan dan mengatasi kesulitan-kesulitan yang dihadapi ibu pada masa menyusui. Tanpa pengetahuan yang baik, akan sulit bagi ayah untuk menjalankan perannya tersebut. Oleh karena itu, ayah harus diikutsertakan dan dilibatkan sedini mungkin dengan menyediakan ruang diskusi bagi ayah pada saat antenatal care khususnya tentang ASI eksklusif dan manfaatnya, kolostrum dan manfaatnya, risiko pemberian makanan prelakteal, usia yang tepat dalam memperkenalkan susu formula, kesulitan-kesulitan menyusui dan cara yang dapat dilakukan ayah untuk membantu mengatasi kesulitan tersebut sehingga ayah dapat terus mendukung ibu untuk menyusui sejak masa prenatal sehingga masa postnatal. Selain itu, perlu adanya Father Support Group sebagai media atau forum berbagi pengalaman dan pengetahuan seputar menyusui sehingga ayah tetap mendukung ibu untuk melanjutkan pemberian ASI sesuai dengan waktu 
yang direkomendasikan oleh WHO. Suasana lingkungan belajar yang saling mendukung dan menghargai sesama orang tua yang bertemu secara rutin dapat merangsang terciptanya interaksi yang baik sehingga melalui kesamaan fase hidup, cerita, pengalaman dan perhatian dapat meningkatkan pengetahuan ayah, membuat ayah menjadi lebih peka terhadap hal-hal yang berkaitan dengan kesehatan anak serta mengenali peran mereka.

\section{Daftar Pustaka}

1. Statistics Indonesia (Badan Pusat Statistik-BPS), National Population and Family Planning Board (BKKBN), and Kementerian Kesehatan (Kemenkes-MOH), and ICF International. Indonesia demographic and health survey 2012. Jakarta: BPS, BKKBN, Kemenkes, and ICF International; 2013.

2. Bar-Yam NB, Darby L. Fathers and breastfeeding: a review of the literature. Journal of Human Lactation. 1997; 13: 45-50.

3. Wolfberg AJ, Michels KB, Shields W, O’Campo P, Bronner Y, Bienstock J. Dads as breastfeeding advocates: results of a randomized controlled trial of an educational intervention. American Journal of Obstetrics and Gynecology. 2004; 191: 708-12.

4. Cohen R, Lange L, Slusser W. A description of a male-focused breastfeeding promotion corporate lactation program. Journal of Human Lactation. 2002; 18: 61-5.

5. Freed GL, Kennard FJ, Schanler RJ. Attitudes of expectant fathers regarding breast-feeding. Pediatrics. 1992; 90: 224-7.

6. Februhartanty J. Strategic roles of fathers in optimizing breastfeeding practices: A study in an urban setting of Jakarta [Dissertation]. Jakarta:
Universitas Indonesia; 2008.

7. Pisacane A, Continisio GI, Aldinucci M, D'Amora S, Continisio P. A controlled trial of father's role in breastfeeding promotion. Electronic article. Pediatrics. 2005; 116(4): e494-8.

8. Arora S, McJunkin C, Wehrer J, Kuhn P. Major factors influencing breastfeeding rates: mother's perception of father's attitude and milk supply. Pediatrics [serial on internet]. 2000 [cited 2013 Jul 11]; 106: e67. Available from: http://pediatrics.aappublications.org/content/106/5/e67.full.html.

9. Scott JA, Shaker I, Reid M. Parental attitudes towards breastfeeding: their association with feeding outcome at hospital discharge. Birth. 2004; 31: 125-31.

10. Falceto OG, Giugliani ERJ,Fernandes CLC. Couples relationships and breastfeeding: is there an association? Journal of Human Lactation. 2004; 20: 46-55.

11. Giugliani ERJ. Common problems during lactation and their management. Jornal de Pediatria (Rio J). 2004; 80 (5 Suppl): S147-54.

12. Februhartanty J, Bardosono S, Septiari AM. Problems during lactation are associated with exclusive breastfeeding in DKI Jakarta Province: Father's potential roles in helping to manage these problems. Malaysian Journal of Nutrition. 2006; 12: 167-80.

13. Coleman WL, Garfield C, Committee on Psychosocial Aspects of Child and Family Health. Fathers and pediatricians: enhancing men's roles in the care and development of their children. Pediatrics. 2004; 113: 140611.

14. Schmidt MM, Sigman-Grant M. Perspectives of low-income fathers' support of breastfeeding: an exploratory study. Journal of Nutrition Education. 1999; 31: 31-7. 